\title{
Kajian Perilaku Pengguna (User) Terhadap Penggunaan Sistem Informasi Industri Kecil Menengah (SI-IKM) Kota Tegal
}

\author{
Andri Widianto $^{1 *}$ dan Aryanto $^{2}$ \\ ${ }^{1}$ D-III Akuntansi, Politeknik Harapan Bersama Tegal, Indonesia \\ ${ }^{2}$ D-III Akuntansi, Politeknik Harapan Bersama Tegal, Indonesia
}

\begin{abstract}
:
Information has an important role for human life, therefore every human being needs information in order to support her daily life. The purpose of this research is to know User Behavior toward Small Medium Industry Information System (SI-IKM) Tegal With The Technology Acceptance Model (TAM) Theory Approach. The population of this research is the user of IKM information system. Samples taken in this study are employees of Department of Labor, Industry of Tegal City, surveyors and perpetrators of IKM using the information system. Sampling technique in this research is purposive sampling. The results of this study in accordance with the approach of Technology Acceptance Model Model (TAM), but for Perceived Usefulness variables have no significant effect on Attitude Toward Using variable.
\end{abstract}

Keywords: Technology Acceptance Model, TAM, SI-IKM

\begin{abstract}
Abstrak:
Informasi memberikan peranan penting bagi kehidupan manusia, oleh karenanya setiap manusia membutuhkan informasi guna menujang kehidupan sehari-harinya. Tujuan penelitian yang ingin dicapai adalah untuk mengetahui perilaku pengguna (user) terhadap penggunaan sistem informasi Industri Kecil Menengah (SI-IKM) Kota Tegal dengan pendekatan teori Technology Acceptance Model (TAM). Populasi penelitian ini adalah pengguna sistem informasi IKM. Sampel yang diambil dalam penelitian ini adalah pegawai Dinas Tenaga Kerja, Perindustrian Kota Tegal serta surveyor dan pelaku IKM yang menggunakan sistem informasi tersebut. Teknik pengambilan sampel dalam penelitian ini adalah purposive sampling. Hasil penelitian ini sesuai dengan pendekatan Teori Technology Acceptance Model (TAM), akan tetapi untuk variabel Perceived Usefulness tidak berpengaruh signifikan terhadap variabel Attitude Toward Using.
\end{abstract}

Kata Kunci: Technology Acceptance Model, TAM, SI-IKM

*Email korespondensi:

Andri Widianto

andriwidi29@gmail.com

\section{PENDAHULUAN}

\section{Latar Belakang}

Informasi memberikan peranan penting bagi kehidupan manusia, oleh 
karenanya setiap manusia membutuhkan informasi guna menujang kehidupan sehariharinya sehingga kebutuhan akan informasi tersebut lambat laun semakin meningkat. Informasi yang berguna adalah informasi yang dapat dijadikan dasar dalam pengambilan keputusan (Bodnar dan Hopwood, 1995) dalam (Khakim, 2011).

Perkembangan teknologi informasi tersebut memberikan berbagai kemudahan pada berbagai aspek kegiatan bisnis. Kemajuan teknologi informasi dapat juga meningkatkan efektivitas dan efisiensi proses bisnis sekaligus Sistem Informasi Manajemennya. Seiring dengan kemajuan teknologi informasi tersebut direspon oleh Dinas Tenaga Kerja, Perindustrian dan Perdagangan Kota Tegal membuat suatu Sistem Informasi Industri Kecil Menengah. Sistem informasi Industri Kecil Mengeah tersebut diharapkan dapat memberikan nilai tambah untuk menunjang semua aktivitas Industri Kecil Menengah.

Sistem informasi tersebut harus dapat diterima dan digunakan oleh seluruh pengguna. Pengguna harus mempertimbangkan manfaat dan kegunaan dalam pemakaian Teknologi Informasi Komunikasi. Pertimbangan tersebut mempengaruhi persepsi pengguna Teknologi Informasi Komunikasi terhadap perilakunya. (Venkatesh dan Moris, 2000) dalam (Khakim, 2011).

Dalam penelitian ini meneliti perilaku pengguna dilihat dari beberapa hal, seperti: Davis (1989) mendefinisikan kemudahan penggunaan (perceived ease of use) sebagai suatu tingkatan dimana seseorang percaya bahwa penggunaan sistem tertentu dapat mengurangi usaha seseorang dalam mengerjakan sesuatu. Persepsi kegunaan (perceived usefulness) merupakan suatu tingkatan dimana seseorang percaya bahwa pengguna suatu sistem tertentu akan dapat meningkatkan prestasi kerja orang tersebut. Sikap pada penggunaan sesuatu menurut Aakers dan Myers (1997) adalah, sikap suka atau tidak suka terhadap penggunaan suatu produk. Sikap suka atau tidak suka terhadap suatu produk ini dapat digunakan untuk memprediksi perilaku niat seseorang untuk menggunakan suatu produk atau tidak menggunakannya. Behavioral intention to use adalah kecenderungan perilaku untuk tetap menggunakan suatu teknologi (Davis, 1989).

Berdasarkan latar belakang diatas, maka penulis tertarik melakukan penelitian dengan judul Kajian Perilaku Pengguna (user) terhadap Penggunaan Sistem Informasi Industri Kecil Menengah (SIMIKM) Kota Tegal dengan Pendekatan Teori Technology Acceptance Model (TAM)

\section{Rumusan Masalah}

Berdasarkan latar belakang diatas, maka dapat dirumuskan rumusan masalah sebagai berikut: Bagaimana Perilaku Pengguna (User) Terhadap Penggunaan Sistem Informasi Industri Kecil Menengah (SI-IKM) Kota Tegal Dengan Pendekatan Teori Technology Acceptance Model (TAM)?

\section{KAJIAN LITERATUR}

\section{Theory of Reasoned Action (TRA)}

Theory of Reasoned Action (TRA) menyatakan bahwa individu akan menggunakan komputer jika mereka mengetahui adanya keuntungan atau hasil positif dalam penggunaan komputer tersebut Fisben dan Ajzen (1975). Individu akan menggunakan TIK jika mempunyai alasan yang tepat dan menguntungkan, contohnya pekerjaan dapat diselesaikan lebih cepat 
dengan hasil yang lebih baik sehingga kinerja individu tersebut dapat dikatakan meningkat. TRA merupakan landasan untuk memperoleh pemahaman yang lebih baik mengenai perilaku pemakai dalam penerimaan dan penggunaan teknologi informasi Davis (1989). Penerimaan sebuah aplikasi TIK bergantung dari bagaimana perilaku individu yang memakai terhadap TIK tersebut.

\section{Technology Acceptance Model (TAM)}

Menurut Davis (1989) TAM adalah sebuah teori sistem informasi yang dirancang untuk menjelaskan bagaimana pengguna mengerti dan menggunakan sebuah teknologi informasi. TAM menggunakan TRA dari Fishbein dan Ajzen (1967) yang digunakan untuk melihat bagaimana tingkat adopsi responden dalam menerima teknologi informasi. Suseno (2009) menggunakan konstruk asli TAM yang dibuat oleh Davis (1989), yaitu persepsi kegunaan (perceived usefulness), persepsi kemudahan penggunaan (perceived ease of use), sikap (attitude), minat perilaku (behavioral intention), penggunaan senyatanya (actual use) dan ditambahkan beberapa konstruk eksternal yaitu, pengalaman (experience), kerumitan (complexity)

\section{Persepsi Kegunaan Penggunaan (Usefulness)}

Persepsi kegunaan (perceived usefulness) merupakan suatu tingkatan dimana seseorang percaya bahwa pengguna suatu sistem tertentu akan dapat meningkatkan prestasi kerja orang tersebut. Berdasarkan definisi tersebut dapat diartikan bahwa kemanfaatan dari penggunaan TIK dapat meningkatkan kinerja, prestasi kerja orang yang menggunakannya.
Thompson et. al (1991) menyimpulkan kemanfaatan teknologi informasi merupakan manfaat yang diharapkan oleh pengguna teknologi informasi dalam melaksanakan tugas. Thompson (1991) juga menyebutkan bahwa individu akan menggunakan TIK jika orang tersebut mengetahui manfaat atau kegunaan (usefulness) positif atas penggunaanya.

\section{Persepsi Kemudahan Penggunaan (Perceived Ease of Use)}

Persepsi kemudahan penggunaan mampu meyakinkan pengguna bahwa TIK yang akan digunakan mudah dan bukan merupakan beban bagi mereka. TIK yang mudah digunakan akan terus dipakai oleh perusahaan. Persepsi kemudahan penggunaan mempengaruhi kegunaan, sikap, minat perilaku dan penggunaan senyatanya, Chau dalam Wiyono (2008).

Davis (1989) mendefinisikan kemudahan penggunaan (perceived ease of use) sebagai suatu tingkatan dimana seseorang percaya bahwa penggunaan sistem tertentu dapat mengurangi usaha seseorang dalam mengerjakan sesuatu. Menurut Goodwin (1987), Silver (1988), dalam Maskur (2005), intensitas penggunaan dan interaksi antara pengguna (user) dengan sistem juga dapat menunjukan kemudahan penggunaan. Sistem yang lebih sering digunakan menunjukan bahwa sistem tersebut lebih dikenal, lebih mudah dioperasikan dan lebih mudah digunakan oleh penggunanya

\section{Sikap Terhadap Penggunaan (Attitude Toward Using)}

Sikap pada penggunaan sesuatu menurut Aakers dan Myers (1997) adalah, sikap suka atau tidak suka terhadap penggunaan suatu produk. Sikap suka atau 
tidak suka terhadap suatu produk ini dapat digunakan untuk memprediksi perilaku niat seseorang untuk menggunakan suatu produk atau tidak menggunakannya. Sikap terhadap penggunaan teknologi (attitude toward using technology), didefinisikan sebagai evaluasi dari pemakai tentang ketertarikannya dalam menggunakan teknologi, Arif Hermawan (2008) dalam Suseno (2009)

\section{Minat Perilaku Penggunaan (Behavioral} Intention to Use)

Behavioral intention to use adalah kecenderungan perilaku untuk tetap menggunakan suatu teknologi (Davis, 1989). Tingkat penggunaan sebuah teknologi komputer pada seseorang dapat diprediksi dari sikap perhatian pengguna terhadap teknologi tersebut, misalnya keinginan menambah peripheral pendukung, motivasi untuk tetap menggunakan, serta keinginan untuk memotivasi pengguna lain. Hermawan (2008) dalam Suseno (2009) mendefinisikan minat perilaku menggunakan teknologi sebagai minat (keinginan) seseorang untuk melakukan perilaku tertentu.

\section{Penggunaan Senyatanya (Actual Use)}

Penggunaan senyatanya (actual system usage) adalah kondisi nyata penggunaan sistem (Davis,1989). Seseorang akan puas menggunakan sistem jika mereka meyakini bahwa sistem tersebut mudah digunakan dan meningkatkan produktifitas mereka, yang tercermin dari kondisi nyata penggunaan (Natalia Tangke, 2004).

Bentuk pengukuran penggunaan senyatanya (actual system usage) adalah frekuensi dan durasi waktu penggunaan terhadap TIK. Penggunaan teknologi sesungguhnya (actual technology use), diukur dengan jumlah waktu yang digunakan untuk berinteraksi dengan teknologi dan frekuensi penggunaan teknologi tersebut.

\section{METODE PENELITIAN}

Populasi penelitian ini adalah pengguna sistem informasi IKM. Dengan teknik pengambilan sampel dalam penelitian ini menggunakan teknik purposive sampling yaitu metode penetapan sampel dengan didasarkan pada kriteri-kriteria tertentu. Sampel yang diambil dalam penelitian ini adalah:
a. Pengguna SI-IKM : 85 Orang
Seluruh Klaster
b. Surveyor IKM : 25 Orang
c. Pegawai Disnakerin : 7 Orang
Total Sampel
: 117 Orang

\section{Teknik Pengumpulan Data}

Metode pengumpulan data dengan kuesioner dimana peneliti dapat memberi penjelasan mengenai tujuan survey dan pertanyaan yang kurang dipahami oleh responden serta tanggapan atas kuesioner dapat langsung dikumpulkan oleh peneliti setelah selesai diisi oleh responden. Pertanyaan yang disajikan dalam kuesioner berupa pertanyaan tertutup yang dibuat dengan menggunakan skala interval.

\section{Uji Kualitas Data}

\section{Evaluasi Model Pengukuran (Outer Model)}

Convergent validity dari model pengukuran dapat dilihat dari korelasi antara skor indikator dengan skor konstruknya (loading factor) dengan kriteria nilai loading factor dari setiap indikator lebih besar dari 0,70 dapat dikatakan valid. Selanjutnya untuk nilai $\mathrm{p}$-value apabila $<0,05$ dianggap signifikan. 
Discriminant validity dinilai dari cross loading pengukuran dengan konstruk. Dapat dilihat dengan melihat loading konstruk laten, yang akan memprediksi indikatornya lebih baik daripada konstruk lainnya. Jika korelasi konstruk dengan pokok pengukuran (setiap indikator) lebih besar daripada ukuran konstruk lainnya maka validitas diskriminan terpenuhi. Pengujian selanjutnya adalah uji reliabilitas konstruk yang dapat diukur dengan 2 kriteria yaitu composite reliability dan cronbach's alpha. Suatu konstruk dinyatakan reliabel jika nilai composite reliability $>0,70$.

\section{Evaluasi Model Struktural (Inner Model)}

Tahap selanjutnya adalah melakukan evaluasi struktural (inner model) yang meliputi uji kecocokan model (model fit), path coefficient, dan R2. Pada uji kecocokan model terdapat 3 indeks pengujian, yaitu average path coefficient (APC), average $R$ - squared (ARS) dan average varians factor (AVIF) dengan kriteria APC dan ARS diterima dengan syarat $p$ - value < 0,05 dan AVIF lebih kecil dari 5 (Mahfud Sholihin dan Dwi Ratmono, 2013).

\section{Uji Hipotesis}

Hasil korelasi antar konstruk diukur dengan melihat path coefficients dan tingkat signifikansinya yang kemudian dibandingkan dengan hipotesis penelitian. Tingkat signifikansi yang dipakai dalam penelitian ini adalah sebesar 5\%. Hipotesis diterima jika nilai p-value $<0,05$

\section{HASIL DAN PEMBAHASAN Convergent Validity}

Dalam buku Machfud dan Dwi (2013) dijelaskan bahwa dalam beberapa kasus, syarat loading di atas 0,70 sering tidak terpenuhi khususnya untuk kuesioner yang baru dikembangkan. Oleh karena itu, loading antara $0,40-0,70$ harus tetap dipertimbangkan untuk dipertahankan.

Selanjutnya dijelaskan pula bahwa, indikator dengan loading $<0,40$ dihapus dari model. Penghapusan indikator dengan loading antara 0,40-0,70 dilakukan apabila indikator tersebut dapat meningkatkan AVE dan composite reliability diatas nilai batasannya. Nilai batasan untuk AVE 0,50 dan composite reliability adalah 0,50. Tabel 1 adalah hasil pengolahan data Convergent Validity.

Berdasarkan Tabel 1, hasil PEU2, PEU3, PEU4, PEU6 memiliki nilai loading > 0,70 yang memenuhi kriteria convergent validity, sedangkan PEU1 dan PEU5 antara 0,40 - 0,70 yang menurut Machfud dan Dwi (2013) dapat dipertimbangkan sudah memenuhi kriteria convergent validity. $P$ value juga telah memenuhi syarat yaitu memliki nilai sebesar $<0,001(<0,05)$ untuk semua indikator.

Hasil dari pengolahan data menunjukkan ke 7 indikator dalam variabel Perceived Usefulness yaitu PU2, PU3, PU4, PU6, PU7 memiliki nilai loading > 0,70 yang memenuhi kriteria convergent validity, sedangkan PU1 antara 0,40 - 0,70 yang menurut Machfud dan Dwi (2013) dapat dipertimbangkan sudah memenuhi kriteria convergent validity. P-value juga telah memenuhi syarat yaitu memliki nilai sebesar $<0,001(<0,05)$ untuk semua indikator.

Hasil dari pengolahan data menunjukkan ke 7 indikator dalam variabel Attitude Toward Using yaitu ATU1 dan ATU3 memiliki nilai loading > 0,70 yang memenuhi kriteria convergent validity, sedangkan ATU2 dan ATU4 antara 0,40 0,70 yang menurut Machfud dan Dwi (2013) dapat dipertimbangkan sudah memenuhi 
kriteria convergent validity. P-value juga telah memenuhi syarat yaitu memliki nilai sebesar $<0,001 \quad(<0,05)$ untuk semua indikator.

Hasil dari pengolahan data menunjukkan ke 7 indikator dalam variabel Behavioral Intention to Use yaitu IU1, IU2, IU3 dan IU4 memiliki nilai loading > 0,70 yang memenuhi kriteria convergent validity. $P$-value juga telah memenuhi syarat yaitu memliki nilai sebesar $<0,001 \quad(<0,05)$ untuk semua indikator.

Hasil dari pengolahan data menunjukkan ke 7 indikator dalam variabel Actual Use yaitu AU1, AU3 dan AU4 memiliki nilai loading > 0,70 yang memenuhi kriteria convergent validity, sedangkan AU2 antara 0,40 - 0,70 yang menurut Machfud dan Dwi (2013) dapat dipertimbangkan sudah memenuhi kriteria convergent validity. P-value juga telah memenuhi syarat yaitu memliki nilai sebesar $<0,001(<0,05)$ untuk semua indikator.

Selanjutnya analisis mengenai standard error, yang pada tabel hasil output combined loadings and cross-loading. dituliskan dengan huruf SE. Semakin kecil standard error dari suatu indikator maka semakin baik atau semakin layak. Standard error yang besar menunjukkan adanya ketidaklayakan model yang disusun, dan diharapkan nilainya relatif kecil yaitu dibawah 0,5 atau 0,4 dan tidak boleh bernilai negatif.

Tabel 1 Hasil Output Combined Loadings and Cross-Loading

\begin{tabular}{|c|c|c|c|c|c|c|c|c|}
\hline Indikator & PEU & PU & ATU & IU & $\mathbf{A U}$ & SE & $P$ value & Keterangan \\
\hline PEU1 & $(0.669)$ & 0.638 & 0.619 & -0.223 & -0.390 & 0.078 & $<0.001$ & Memenuhi CV* \\
\hline PEU2 & $(0.813)$ & -0.440 & -0.178 & 0.403 & -0.084 & 0.075 & $<0.001$ & Memenuhi CV \\
\hline PEU3 & $(0.815)$ & 0.021 & -0.693 & 0.125 & 0.145 & 0.075 & $<0.001$ & Memenuhi CV \\
\hline PEU4 & $(0.760)$ & 0.274 & -0.103 & -0.043 & 0.045 & 0.076 & $<0.001$ & Memenuhi CV \\
\hline PEU5 & $(0.690)$ & -0.594 & 0.281 & -0.303 & 0.251 & 0.078 & $<0.001$ & Memenuhi CV \\
\hline PEU6 & $(0.754)$ & -0.355 & -0.385 & -0.708 & 0.051 & 0.091 & $<0.001$ & Memenuhi CV \\
\hline PU1 & 0.556 & $(0.652)$ & -0.103 & -0.634 & 0.318 & 0.080 & $<0.001$ & Memenuhi CV \\
\hline PU2 & 0.632 & $(0.722)$ & 0.626 & -0.529 & -0.107 & 0.077 & $<0.001$ & Memenuhi CV \\
\hline PU3 & -0.436 & $(0.817)$ & -0.259 & -0.119 & 0.105 & 0.075 & $<0.001$ & Memenuhi CV \\
\hline PU4 & -0.349 & $(\mathbf{0 . 7 9 8 )}$ & -0.715 & 0.260 & 0.186 & 0.076 & $<0.001$ & Memenuhi CV \\
\hline PU5 & -0.679 & $(0.738)$ & 0.374 & 0.503 & -0.357 & 0.077 & $<0.001$ & Memenuhi CV \\
\hline PU6 & -0.416 & $(\mathbf{0 . 8 3 6 )}$ & 0.237 & 0.019 & -0.007 & 0.075 & $<0.001$ & Memenuhi CV \\
\hline PU7 & -0.714 & $(\mathbf{0 . 8 5 3 )}$ & -0.101 & 0.016 & -0.075 & 0.075 & $<0.001$ & Memenuhi CV \\
\hline ATU1 & 0.691 & -0.363 & $(0.711)$ & -0.960 & 0.537 & 0.081 & $<0.001$ & Memenuhi CV \\
\hline ATU2 & -0.001 & 0.395 & $(0.637)$ & -0.274 & 0.153 & 0.079 & $<0.001$ & Memenuhi CV \\
\hline ATU3 & -0.264 & 0.530 & $(0.721)$ & -0.215 & -0.150 & 0.077 & $<0.001$ & Memenuhi CV \\
\hline ATU4 & 0.561 & -0.502 & $(0.628)$ & -0.808 & 0.463 & 0.079 & $<0.001$ & Memenuhi CV \\
\hline IU1 & 0.775 & 0.123 & 0.143 & $(0.715)$ & 0.156 & 0.077 & $<0.001$ & Memenuhi CV \\
\hline IU2 & 0.974 & 0.865 & 1.368 & $(0.775)$ & -0.439 & 0.091 & $<0.001$ & Memenuhi CV \\
\hline IU3 & 0.367 & -0.383 & 0.017 & $(0.868)$ & 0.150 & 0.074 & $<0.001$ & Memenuhi CV \\
\hline IU4 & 0.210 & 0.459 & -0.019 & $(0.775)$ & 0.018 & 0.076 & $<0.001$ & Memenuhi CV \\
\hline AU1 & -1.901 & 0.268 & -0.914 & 0.520 & $(0.791)$ & 0.088 & $<0.001$ & Memenuhi CV \\
\hline AU2 & -1.515 & 0.604 & -0.845 & 0.295 & $(0.683)$ & 0.078 & $<0.001$ & Memenuhi CV \\
\hline AU3 & 0.566 & 0.097 & 0.554 & -0.215 & $(\mathbf{0 . 8 5 1})$ & 0.075 & $<0.001$ & Memenuhi CV \\
\hline AU4 & 1.041 & -0.621 & 0.318 & -0.134 & $(\mathbf{0 . 8 8 0})$ & 0.074 & $<0.001$ & Memenuhi CV \\
\hline
\end{tabular}

$*$ Ket.: $C V=$ convergent validity

\section{Sumber: Data primer yang diolah, 2018}


Berdasarkan Tabel 1, dapat disimpulkan bahwa keseluruhan indikator memiliki kelayakan model. Variabel Perceived Ease of Use (PEU), Perceived Usefulness (PU), Attitude Toward Using (ATU), Behavioral Intention to Use (IU) dan Actual Use (AU) memilki nilai standard error yang sesuai kriteria yaitu $<0,5$ dan dianggap layak.

\section{Discriminant Validity}

Discriminant validity dinilai dari cross loading pengukuran dengan konstruk. Dapat dilihat dengan melihat loading konstruk laten, yang akan memprediksi indikatornya lebih baik daripada konstruk lainnya. Jika korelasi konstruk dengan pokok pengukuran (setiap indikator) lebih besar daripada ukuran konstruk lainnya maka validitas diskriminan terpenuhi.

Tabel 2 Nilai Loading Konstruk Laten Indikator dan Konstruk Lainnya

\begin{tabular}{|c|c|c|c|c|c|c|c|c|}
\hline \multirow[b]{2}{*}{ Indikator } & \multirow[b]{2}{*}{ Loading } & & \multicolumn{5}{|c|}{ Nilai loading ke konstruk lain } & \multirow[b]{2}{*}{ Keterangan } \\
\hline & & & PEU & $\mathbf{P U}$ & ATU & IU & $\mathbf{A U}$ & \\
\hline PEU1 & $(\mathbf{0 . 6 6 9 )}$ & $>$ & & 0.638 & 0.619 & -0.223 & -0.390 & Memenuhi DV \\
\hline PEU2 & $(0.813)$ & $>$ & & -0.440 & -0.178 & 0.403 & -0.084 & Memenuhi DV \\
\hline PEU3 & $(0.815)$ & $>$ & & 0.021 & -0.693 & 0.125 & 0.145 & Memenuhi DV \\
\hline PEU4 & $(0.760)$ & $>$ & & 0.274 & -0.103 & -0.043 & 0.045 & Memenuhi DV \\
\hline PEU5 & $(0.690)$ & $>$ & & -0.594 & 0.281 & -0.303 & 0.251 & Memenuhi DV \\
\hline PEU6 & $(0.754)$ & $>$ & & -0.355 & -0.385 & -0.708 & 0.051 & Memenuhi DV \\
\hline PU1 & $(0.652)$ & $>$ & 0.556 & & -0.103 & -0.634 & 0.318 & Memenuhi DV \\
\hline PU2 & $(\mathbf{0 . 7 2 2})$ & $>$ & 0.632 & & 0.626 & -0.529 & -0.107 & Memenuhi DV \\
\hline PU3 & $(0.817)$ & $>$ & -0.436 & & -0.259 & -0.119 & 0.105 & Memenuhi DV \\
\hline PU4 & $(\mathbf{0 . 7 9 8 )}$ & $>$ & -0.349 & & -0.715 & 0.260 & 0.186 & Memenuhi DV \\
\hline PU5 & (0.738) & $>$ & -0.679 & & 0.374 & 0.503 & -0.357 & Memenuhi DV \\
\hline PU6 & $(0.836)$ & $>$ & -0.416 & & 0.237 & 0.019 & -0.007 & Memenuhi DV \\
\hline PU7 & $(0.853)$ & $>$ & -0.714 & & -0.101 & 0.016 & -0.075 & Memenuhi DV \\
\hline ATU1 & $(0.711)$ & $>$ & 0.691 & -0.363 & & -0.960 & 0.537 & Memenuhi DV \\
\hline ATU2 & $(0.637)$ & $>$ & -0.001 & 0.395 & & -0.274 & 0.153 & Memenuhi DV \\
\hline ATU3 & $(0.721)$ & $>$ & -0.264 & 0.530 & & -0.215 & -0.150 & Memenuhi DV \\
\hline ATU4 & $(0.628)$ & $>$ & 0.561 & -0.502 & & -0.808 & 0.463 & Memenuhi DV \\
\hline IU1 & $(0.715)$ & $>$ & 0.675 & 0.123 & 0.143 & & 0.156 & Memenuhi DV \\
\hline IU2 & $(0.775)$ & $>$ & 0.674 & 0.565 & 0.368 & & -0.439 & Memenuhi DV \\
\hline IU3 & $(0.868)$ & $>$ & 0.367 & -0.383 & 0.017 & & 0.150 & Memenuhi DV \\
\hline IU4 & $(0.775)$ & $>$ & 0.210 & 0.459 & -0.019 & & 0.018 & Memenuhi DV \\
\hline AU1 & $(0.791)$ & $>$ & -1.901 & 0.268 & -0.914 & 0.520 & & Memenuhi DV \\
\hline AU2 & $(0.683)$ & $>$ & -1.515 & 0.604 & -0.845 & 0.295 & & Memenuhi DV \\
\hline AU3 & $(0.851)$ & $>$ & 0.566 & 0.097 & 0.554 & -0.215 & & Memenuhi DV \\
\hline AU4 & $(\mathbf{0 . 8 8 0})$ & $>$ & 1.041 & -0.621 & 0.318 & -0.134 & & Memenuhi DV \\
\hline
\end{tabular}

Ket.: $D V=$ Discriminant Validity

Berdasarkan data di atas, keseluruhan indikator telah memenuhi kriteria validitas diskriminan. Variabel $P E U$ yang memiliki 6 indikator yang dilambangkan dengan PEU1 sampai dengan
PEU6. PEU1 memiliki nilai loading 0,669 yang nilai loading-nya lebih besar dari loading ke konstruk lain yaitu 0,638, 0,619, $-0,223$ dan $-0,390$ dan ke 5 indikator lainnya 
juga memiliki nilai loading yang lebih besar dari nilai loading ke konstruk lain.

Variabel Perceived Usefulness (PU) yang memiliki 7 indikator yang dilambangkan dengan PU1 sampai dengan PU7. PU1 memiliki nilai loading 0,652 yang nilai loading-nya lebih besar dari loading ke konstruk lain yaitu $0,556,-0,103,-0,634$ dan 0,318 dan ke 6 indikator lainnya juga memiliki nilai loading yang lebih besar dari nilai loading ke konstruk lain.

Variabel persepsi atas Attitude Toward Using (ATU) memiliki 4 indikator yang dilambangkan dengan ATU1 sampai dengan ATU4. ATU 1 memiliki nilai loading 0,711 yang nilai loading-nya lebih besar dari loading ke konstruk lain yaitu $0,691,-0,363,-0,960$ dan 0,537 dan ke 3 indikator lainnya juga memiliki nilai loading yang lebih besar dari nilai loading ke konstruk lain. Berdasarkan uraian tersebut, dapat disimpulkan bahwa keseluruhan indikator telah memenuhi kriteria validitas diskriminan.

Variabel persepsi atas Behavioral Intention to Use (IU) memiliki 4 indikator yang dilambangkan dengan IU1 sampai dengan IU4. IU1 memiliki nilai loading 0,715 yang nilai loading-nya lebih besar dari loading ke konstruk lain yaitu 0,675, 0,123, 0,143 dan 0,156 dan ke 3 indikator lainnya juga memiliki nilai loading yang lebih besar dari nilai loading ke konstruk lain. Berdasarkan uraian tersebut, dapat disimpulkan bahwa keseluruhan indikator telah memenuhi kriteria validitas diskriminan.

Variabel persepsi atas Actual Use (AU) memiliki 4 indikator yang dilambangkan dengan AU1 sampai dengan AU4. AU1 memiliki nilai loading 0,791 yang nilai loading-nya lebih besar dari loading ke konstruk lain yaitu -0,901, 0,268,
-0,914 dan 0,520 dan ke 3 indikator lainnya juga memiliki nilai loading yang lebih besar dari nilai loading ke konstruk lain. Berdasarkan uraian tersebut, dapat disimpulkan bahwa keseluruhan indikator telah memenuhi kriteria validitas diskriminan.

\section{Composite Realibility}

Pengujian selanjutnya adalah uji reliabilitas konstruk yang dapat diukur dengan 2 kriteria yaitu composite reliability dan cronbach's alpha. Suatu konstruk dinyatakan reliabel jika nilai composite reliability $>0,70$. Hasil dari output latent variable coefficients disajikan pada Tabel 3.

Tabel 3 Hasil Output Latent Variabel

Coefficients

\begin{tabular}{|l|c|c|c|c|c|c|c|}
\hline & PEU & PU & ATU & IU & AU & Kriteria & Ket \\
\hline Composite & 0.82 & 0.91 & 0.72 & 0.70 & 0.77 & $>0,70$ & Reliabel \\
\hline Cronbach's & 0.73 & 0.88 & 0.73 & 0.76 & 0.72 & $\begin{array}{c}\geq 0,5 \text { baik } \\
\geq 0,3 \text { cukup }\end{array}$ & Reliabel \\
\hline
\end{tabular}

Sumber : Data primer yang diolah, 2018

Tabel 4 Hasil Output Model Fit Indices

\begin{tabular}{|l|c|c|c|c|}
\hline & Indeks & p value & Kriteria & Ket \\
\hline $\begin{array}{l}\text { Average path } \\
\text { coefficient } \\
\text { (APC) }\end{array}$ & 0.508 & $\mathrm{P}<0.001$ & $\mathrm{p}<0,05$ & Diterima \\
\hline $\begin{array}{l}\text { Average R- } \\
\text { squared } \\
\text { (ARS) }\end{array}$ & 0.561 & $\mathrm{P}<0.001$ & $\mathrm{p}<0,05$ & Diterima \\
\hline $\begin{array}{l}\text { Average } \\
\text { block VIF } \\
\text { (AVIF) }\end{array}$ & $\begin{array}{l}2.883, \\
\text { acceptable if } \\
<=5, \text { ideally } \\
<=3.3\end{array}$ & & AVIF $<5$ & Diterima \\
\hline
\end{tabular}

Sumber : Data primer yang diolah, 2018

Berdasarkan Tabel 3, hasil tersebut menunjukkan composite reliability dari masing-masing konstruk, yaitu Perceived Ease of Use (PEU) 0,820, Perceived Usefulness (PU) 0,907, Attitude Toward Using (ATU) 0,716, Behavioral Intention to Use (IU) 0,721 dan Actual Use (AU) 0,772. 
Hasil dari cronbach's alpha juga menunjukkan bahwa Perceived Ease of Use (PEU) 0,730, Perceived Usefulness (PU) 0,879, Attitude Toward Using (ATU) 0,732, Behavioral Intention to Use (IU) 0,761 dan Actual Use (AU) 0,719. Berdasarkan hasil dari composite reliability dan cronbach's alpha, dapat disimpulkan bahwa keseluruhan variabel telah memenuhi kriteria composite reliability.

\section{Evaluasi Model Struktural (Inner Model)}

Tahap selanjutnya adalah melakukan evaluasi struktural (inner model) yang meliputi uji kecocokan model (model fit), path coefficient, dan $\mathrm{R}_{2}$. Pada uji kecocokan model terdapat 3 indeks pengujian, yaitu average path coefficient (APC), average $R$ - squared (ARS) dan average varians factor (AVIF) dengan kriteria APC dan ARS diterima dengan syarat $p$ - value < 0,05 dan AVIF lebih kecil dari 5 (Mahfud Sholihin dan Dwi Ratmono, 2013). Hasil output model fit indices yang disajikan dalam Tabel 4. Hasil output di atas, menjelaskan bahwa APC memiliki indeks sebesar 0,508 dengan nilai $p$-value < 0,001 . Sedangkan ARS memiliki indeks sebesar 0,561 dengan $p-$ value $<0,001$. Berdasarkan kriteria, APC sudah memenuhi kriteria karena memiliki nilai $\mathrm{p}<0,001$. Begitu pula dengan nilai $\mathrm{p}$ dari ARS yaitu $\mathrm{p}$ $<0,001$. Nilai AVIF yang harus $<5$ sudah terpenuhi karena berdasarkan data tersebut AVIF nilainya 2,883. Dengan demikian, maka inner model dapat diterima.

\section{Hasil Uji Hipotesis}

Hasil korelasi antar konstruk diukur dengan melihat path coefficients dan tingkat signifikansinya yang kemudian dibandingkan dengan hipotesis penelitian. Tingkat signifikansi yang dipakai dalam penelitian ini adalah sebesar 5\%. Tabel 5 adalah hasil penelitian dari effect size yang telah diperoleh berdasarkan pengolahan data. Gambar 1 merupakan gambar hasil penelitian dari effect size yang telah diperoleh berdasarkan pengolahan data.

Tabel 5 Hasil Output Direct Effects

\begin{tabular}{|c|c|c|c|c|c|c|}
\hline \multirow{4}{*}{$\begin{array}{c}\text { Kriteria } \\
\text { coefficie }\end{array}$} & $\begin{array}{c}\text { Varia } \\
\text { bel }\end{array}$ & PEU & PU & ATU & IU & AU \\
\cline { 2 - 7 } & PU & - & - & - & - & - \\
\cline { 2 - 7 } & ATU & -0.803 & -0.041 & - & - & - \\
\cline { 2 - 7 } & IU & - & 0.273 & -0.458 & - & - \\
\cline { 2 - 7 } & AU & - & - & - & 0.590 & - \\
\hline p-values & PEU & - & - & - & - & - \\
\cline { 2 - 7 } & PU & $<0.001$ & - & - & - & - \\
\cline { 2 - 7 } & ATU & $<0.001$ & 0.329 & - & - & - \\
\cline { 2 - 7 } & IU & - & 0.001 & $<0.001$ & - & - \\
\cline { 2 - 7 } & AU & - & - & - & $<0.001$ & - \\
\hline \multirow{4}{*}{$\begin{array}{c}\text { Effect } \\
\text { sizes for } \\
\text { path }\end{array}$} & PEU & - & - & - & - & - \\
\cline { 2 - 7 } & PU & 0.780 & - & - & - & - \\
\cline { 2 - 7 } & ATU & 0.617 & 0.026 & - & - & - \\
\cline { 2 - 7 } & IU & - & 0.169 & 0.305 & - & - \\
\cline { 2 - 7 } & AU & - & - & - & 0.348 & - \\
\hline
\end{tabular}

Sumber: Data primer yang diolah, 2018

\section{Gambar 1 Model Penelitian}

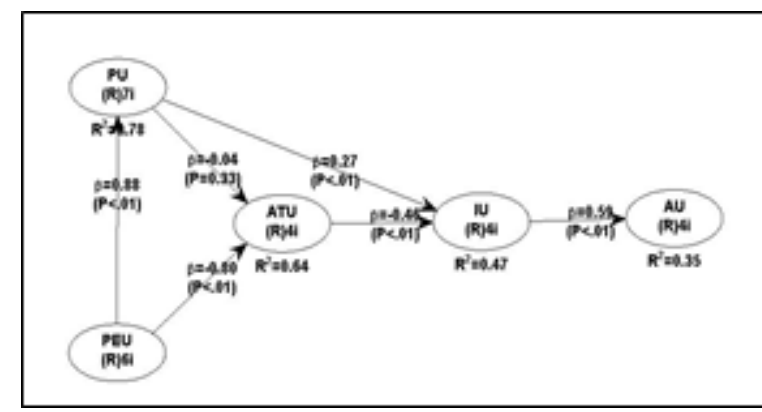

Sumber : Data primer yang diolah, 2018

Keterangan:

PEU = Perceived Ease of Use

PU = Perceived Usefulness

ATU = Attitude Toward Using

IU = Behavioral Intention to Use

$\mathrm{AU}=$ Actual Use

Berikut ini penjelasan hasil uji hipotesis yang diuraikan sebagai berikut : 


\section{Hipotesis 1}

Variabel Perceived Ease of Use berpengaruh signifikan terhadap variabel Perceived Usefulness. Hal ini dikarenakan nilai pvalue $=0,01$ dimana nilai $\mathrm{p}$-value $<0,05$. Hipotesis diterima jika nilai p-value $<0,05$. Nilai $\mathrm{R}^{2}$ dapat dilihat pada effect size, dimana nilainya sebesar 0,780 berarti bahwa variabel Perceived Ease of Use memengaruhi variabel Perceived Usefulness sebesar $78,0 \%$ dan sisanya 22,0\% dipengaruhi oleh variabel lainnya.

\section{Hipotesis 2}

Variabel Perceived Usefulness tidak berpengaruh signifikan terhadap variabel Attitude Toward Using. Hal ini dikarenakan nilai $\mathrm{p}$-value $=0,33$ dimana nilai $\mathrm{p}$-value $>$ 0,05 . Hipotesis diterima jika nilai p-value $<0,05$. Nilai $\mathrm{R}^{2}$ dapat dilihat pada effect size, dimana nilainya sebesar 0,026 berarti bahwa variabel Perceived Usefulness memengaruhi variabel Attitude Toward Using hanya sebesar 2,6\% dan sisanya $97,4 \%$ dipengaruhi oleh variabel lainnya.

\section{Hipotesis 3}

Variabel Perceived Ease of Use berpengaruh signifikan terhadap variabel Attitude Toward Using. Hal ini dikarenakan nilai $\mathrm{p}$-value $=$ 0,01 dimana nilai $\mathrm{p}$-value $<0,05$. Hipotesis diterima jika nilai $p$-value $<0,05$. Nilai $R^{2}$ dapat dilihat pada effect size, dimana nilainya sebesar 0,617 berarti bahwa variabel Perceived Ease of Use memengaruhi variabel Attitude Toward Using sebesar $61,7 \%$ dan sisanya $38,3 \%$ dipengaruhi oleh variabel lainnya.

\section{Hipotesis 4}

Variabel Perceived Usefulness berpengaruh signifikan terhadap variabel Behavioral Intention to Use. Hal ini dikarenakan nilai $\mathrm{p}$ - value $=0,01$ dimana nilai $\mathrm{p}$-value $<0,05$ Nilai $\mathrm{R}^{2}$ dapat dilihat pada effect size, dimana nilainya sebesar 0,169 berarti bahwa variabel Perceived Usefulness memengaruhi variabel Behavioral Intention to Use sebesar $16,9 \%$ dan sisanya $83,1 \%$ dipengaruhi oleh variabel lainnya.

\section{Hipotesis 5}

Variabel Attitude Toward Using berpengaruh signifikan terhadap variabel Behavioral Intention to Use. Hal ini dikarenakan nilai $\mathrm{p}$-value $=0,01$ dimana nilai $p$-value $<0,05$. Nilai $R^{2}$ dapat dilihat pada effect size, dimana nilainya sebesar 0,305 berarti bahwa variabel Attitude Toward Using memengaruhi variabel Behavioral Intention to Use sebesar 30,5\% dan sisanya $69,5 \%$ dipengaruhi oleh variabel lainnya.

\section{Hipotesis 6}

Variabel Behavioral Intention to Use berpengaruh signifikan terhadap variabel Actual Use. Hal ini dikarenakan nilai pvalue $=0,01$ dimana nilai $\mathrm{p}$-value $<0,05$. Nilai $\mathrm{R}^{2}$ dapat dilihat pada effect size, dimana nilainya sebesar 0,348 berarti bahwa variabel Behavioral Intention to Use memengaruhi variabel Actual Use sebesar $34,8 \%$ dan sisanya $65,2 \%$ dipengaruhi oleh variabel lainnya.

\section{Variabel Perceived Ease of Use Berpengaruh Signifikan Terhadap Variabel Perceived Usefulness}

Hal ini dikarenakan nilai $\mathrm{p}$-value $=$ 0,01 dimana nilai $p$-value $<0,05$. Hipotesis diterima jika nilai $\mathrm{p}$-value $<0,05$. Sehingga Perceived Ease of Use berpengaruh signifikan terhadap variabel Perceived Usefulness. Persepsi kemudahan pengguna dalam penggunaan sistem informasi Industri 
Kecil Menengah (SIM-IKM) Kota Tegal sangat berpengaruh terhadap persepsi kegunaannya. Hal ini terlihat responden pengguna Sistem Informasi Manajamen (SIM-IKM) yakin bahwasannya dapat diakses dengan mudah melalui smartphone, kemudian susunaan menu juga tidak menyulitkan para pengguna dan fitur-fitur yang tersedia dalam Sistem Informasi IKM (SIM-IKM) tersebut cukup menarik.

Berdasarkan komponen-komponen tersebut diatas berpengaruh terhadap persepsi kegunaan (Perceived Usefulness) sehingga Sistem Informasi Manajeman IKM (SIM -IKM) dapat meningkatkan efektifitas dalam mengerjakan tugas pendataan survei Industri Kecil Menengah, Hilangnya data IKM Kota Tegal, dan yang terpenting adalah menghemat Waktu, Biaya, dan Tenaga dalam Pengaplikasian Sistem Informasi Manajeman (SIM-IKM) Kota Tegal

Variabel Perceived Usefulness Tidak Berpengaruh Signifikan Terhadap Variabel Attitude Toward Using

Hal ini dikarenakan nilai $\mathrm{p}$-value $=$ 0,33 dimana nilai $p$-value $>0,05$. Hipotesis ditolak jika nilai $\mathrm{p}$-value $>0,05$. Sehingga Perceived Usefulness tidak berpengaruh signifikan terhadap variabel Attitude Toward Using. Persepsi Kegunaan (Perceived Usefulness) seseorang percaya bahwa pengguna suatu sistem tertentu akan dapat meningkatkan prestasi kerja orang tersebut. Sikap pada penggunaan sesuatu menurut Aakers dan Myers (1997) adalah, sikap suka atau tidak suka terhadap penggunaan suatu produk. Sikap suka atau tidak suka terhadap suatu produk ini dapat digunakan untuk memprediksi perilaku niat seseorang untuk menggunakan suatu produk atau tidak menggunakannya.
Bahwa pada dasarnya manfaat dari penggunaan Teknologi Informasi melalui Sistem Informasi IKM dapat meningkatkan kinerja dan bisa dengan cepat akses data tentang Industri Kecil Menengah (IKM) di Kota Tegal, akan tetapi mereka (User) enggan dalam memberikan informasi terkait dengan data pribadi dan model otorisasi Sandi dengan berbagai alasan.

\section{Variabel Perceived Ease of Use Berpengaruh Signifikan Terhadap Variabel Attitude Toward Using}

Hal ini dikarenakan nilai $\mathrm{p}$-value $=$ 0,01 dimana nilai $\mathrm{p}$-value $<0,05$. Hipotesis diterima jika nilai $\mathrm{p}$-value $<0,05$. Sehingga Variabel Perceived Ease of Use berpengaruh signifikan terhadap variabel Attitude Toward Using. Persepsi kemudahan penggunaan mampu meyakinkan pengguna Sistem Informasi Manajemen (SIM-IKM) bahwa sistem informasi tersebut mudah dan bukan merupakan suatu beban untuk penggunanya. Atas kesadaran itu lah, pengguna (User) sadar bahwasannya model otorisasi login, model penyandian/enkripsi serta deskripsi diri dalam mengakses sistem merupakan upaya untuk menjaga keamanan Sistem Informasi Manajeman (SIM-IKM) sehingga mereka bisa menyesuaikan dengan sistem tersebut ketika menggunakannya.

\section{Variabel Perceived Usefulness Berpengaruh Signifikan Terhadap Variabel Behavioral Intention to Use}

Hal ini dikarenakan nilai $\mathrm{p}$-value $=$ 0,01 dimana nilai $\mathrm{p}$-value $<0,05$. Hipotesis diterima jika nilai $\mathrm{p}$-value $<0,05$. Sehingga Variabel Perceived Usefulness berpengaruh signifikan terhadap variabel Behavioral Intention to Use. Perceived Usefulness menyimpulkan bahwa teknologi informasi yang mereka (User) gunakan memberikan 
manfaatuntuk menyelesaikan tugas terkait dengan Industri Kecil Menengah Kota Tegal sehingga berpengaruh terhadap Behavioral intention to use yaitu kecenderungan perilaku untuk tetap menggunakan suatu teknologi (Davis, 1989).

Tingkat penggunaan sistem informasi manajemen tersebut mendapat perhatian pengguna terhadap teknologi tersebut dengan menambah peripheral pendukung seperti Software download dan menambahkan anti virus, dan yang terpenting adalah berkeinginan untuk memotivasi pengguna lain untuk menggunakan Sistem Informasi Manajeman IKM (SIM-IKM).

\section{Variabel Attitude Toward Using} Berpengaruh Signifikan Terhadap Variabel Behavioral Intention to Use

Hal ini dikarenakan nilai $\mathrm{p}$-value $=$ 0,01 dimana nilai $\mathrm{p}$-value $<0,05$. Hipotesis diterima jika nilai $\mathrm{p}$-value $<0,05$. Sehingga Variabel Attitude Toward Using berpengaruh signifikan terhadap variabel Behavioral Intention to Use. Sikap pada penggunaan sesuatu menurut Aakers dan Myers (1997) adalah, sikap suka atau tidak suka terhadap penggunaan suatu produk. Sikap terhadap penggunaan teknologi (attitude toward using technology), didefinisikan sebagai evaluasi dari pemakai tentang ketertarikannya dalam menggunakan teknologi, Arif Hermawan (2008) dalam Suseno (2009) oleh karena rasa keteratrikannya tersebut Sistem Informasi IKM membrikan rasa nyaman kepada pengguna (User) sehingga memepengaruhi masyarakat untuk menggunakan sistem informasi tersebut.
Variabel Behavioral Intention to Use Berpengaruh Signifikan Terhadap Variabel Actual Use

Hal ini dikarenakan nilai $\mathrm{p}$-value $=$ 0,01 dimana nilai $p$-value $<0,05$. Hipotesis diterima jika nilai $\mathrm{p}$-value $<0,05$. Sehingga Variabel Behavioral Intention to Use berpengaruh signifikan terhadap variabel Actual Use. Behavioral intention to use adalah kecenderungan perilaku untuk tetap menggunakan suatu teknologi (Davis, 1989). Pengguna (User) masih menggunakan Sistem Informasi Manajeman (SIM-IKM) dengan menambah bebrapa fitur dan mereka (user) puas dengan dampak dari penggunaan sistem tersebut sehingga mereka (user) sering membuka sistem informasi tersebut dan menyampaikan kepuasan menggunakan sistem tersebut kepada orang lain. Sehinga orang lain / masyarakat dapat juga mengakses sistem infrormasi tersebut.

\section{KESIMPULAN DAN SARAN \\ Kesimpulan}

Adapun kesimpulan dalam penelitian ini adalah sebagai berikut: TAM mempunyai tujuan menjelaskan dan memprediksikan penerimaan pengguna terhadap suatu teknologi informasi. Dalam penelitian ini variabel Perceived Usefulness tidak berpengaruh signifikan terhadap variabel Attitude Toward Using. Pada dasarnya masyarakat sudah menyadari manfaat dari penggunaan Teknologi Informasi melalui Sistem Informasi IKM dapat meningkatkan kinerja sehingga orang-orang yang memanfaatkanya bisa dengan cepat akses data tentang Industri Kecil Menengah (IKM) di Kota Tegal. Akan tetapi pelaku IKM Kota Tegal (user) enggan dalam memberikan informasi terkait dengan data pribadi dan 
model otorisasi sandi dengan berbagai alasan.

\section{Saran}

Adapun saran dalam penelitian ini adalah sebagai berikut:

1. Adanya kerja sama dari berbagai pihak Disnakerin KotaTegal, Pelaku IKM dan Akademisi untuk mensosialiasikan Sistem Informasi Manajamen IKM (SIM-IKM)

2. Pelaku IKM seharusnya lebih terbuka dengan Teknologi sehingga bisa bersaing dengan IKM yang lain tidak hanya lingkup lokal, nasional, bahkan internasional

\section{DAFTAR PUSTAKA}

Davis, F. D. (2005, Desember 23). Measurement Scales for Perceived Usefulness and Perceived Ease of Use. Diambil kembali dari http://wings.buffalo.edu/mgmt/cours es/mgtsand/ Succes/davis.html

Ghozali, I. (t.thn.). Structural Equation Modeling Metode Alternatif Dengan Partial Least Square. Semarang: Badan Penerbit Undip.

Jogiyanto. (2000). Sistem Informasi Berbasis Komputer. Yogyakarta: BPFE.
Kadir, A. (2003). Pengenalan Sistem Informasi. Yogyakarta: ANDI.

Khakim, K. N. (2011). Analisis FaktorFaktor Yang Memepengaruhi Penerimaan dan Penggunaan Software Akuntansi MYOB Dengan Menggunakan Pendekatan Technologi Accepatance Model (TAM).

Malholtra, Y. D. (1999). Extending The Technology Accaptance Model to Account for Social Influence.

Natigor, F. (2006, 1 16). Teknologi Informasi Berdasarkan Aspek Perilaku (Behavior Aspect). Diambil kembali dari http://library.usu.ac.id

Suseno. (2009). Analisis Faktor-Faktor Penerimaan Karyawan PT KAI (persero) terhadap Sistem E-Ticket di Semarang : Pendekatan TAM. Jurnal Jurusan Akuntansi Fakultas Ekonomi Universitas Diponegoro.

Tagke, N. (2008). Analisa Penerimaan Penerapan TABK dengan Menggunakan TAM pada BPK-RI. Diambil kembali dari http:puslit.petra

Wibowo, A. (2008). Kajian Tentang PErilaku Pengguna Sistem Informasi Dengan Pendekatan Technologi Acceptance Model. 